\title{
Fenomenología de la pólis y torsión del Dasein: dialéctica y hermenéutica en la temprana interpretación gadameriana de la ética platónica
}

\author{
Phenomenology of the pólis and torsion of Dasein: dialectic \\ and hermeneutics in the early Gadamerian interpretation of \\ Plato's ethics
}

FACUNDO BEY

Resumen: El objetivo de este artículo es presentar y analizar las principales hipótesis de Hans-Georg Gadamer en su libro de 1931 Platos dialektische Ethik. Phänomenologische Interpretationen zum Philebos en relación con las nociones de pólis, aretê, tó agathón y Dasein. Luego, se intentará demostrar que en este trabajo temprano de Gadamer se formula la primera producción filosófico-política de relevancia del autor, expresada en forma de diálogo crítico con Martin Heidegger, a partir de las nuevas posibilidades interpretativas que la filología y fenomenología le abrieron para el estudio de Platón y su filosofía. Esta obra temprana, además, habría sentado las bases de los futuros desarrollos de la hermenéutica filosófica, en particular, con relación a la caracterización de la estructura dialógico-dialéctica de la comprensión y al vínculo entre éthos, práxis y lógos.

Palabras clave: Dialéctica; Hermenéutica Filosófica; Pólis; Dasein; Gadamer; Heidegger.

\begin{abstract}
The aim of this paper is to present and analyse the main hypotheses of Hans-Georg Gadamer in his 1931 book Platos dialektische Ethik. Phänomenologische Interpretationen zum Philebos regarding the notions of pólis, aretê, tó agathón y Dasein. Then, it will be attempted to show that in this early book of Gadamer is his first relevant philosophical-political work, expressed in the form of a critical dialogue with Martin Heidegger, departing from the new interpretative possibilities that philology and phenomenology opened to Gadamer's studies on Plato's philosophy. This early work, moreover, would have laid the foundations for the future developments of philosophical hermeneutics, in particular, regarding the characterization of the dialecticaldialogical structure of understanding and the relationship among éthos, práxis and lógos.
\end{abstract}

Keywords: Dialectic; Philosophical Hermeneutics; Pólis; Dasein; Gadamer; Heidegger.

Recibido: 18/08/2018. Aceptado: 25/01/2019.

* El autor es Dr. en Filosofía por la Universidad Nacional de General San Martín (EH-UNSAM), Becario del Consejo Nacional de Investigaciones Científicas y Técnicas (CONICET), Investigador del Instituto de Filosofía "Ezequiel de Olaso" - Centro de Investigaciones Filosóficas (CIF) / CONICET y Profesor Titular de Ciencia Política de la Universidad del Salvador. Sus principales líneas de investigación son la recepción de la filosofía política platónica en la filosofía de Hans-Georg Gadamer y en la filosofía y filologías alemanas entre 1919 y 1945, con especial énfasis en las figuras de la soberanía y de la utopía. Publicaciones recientes: "La poesía como diálogo: consideraciones en torno a Plato und die Dichter de Hans-Georg Gadamer", Boletín de Estética, Año XIII, Verano 2016-2017, N 38, pp. 7-43; "El ensayo de Hans-Georg Gadamer sobre el Protréptico aristotélico: ética y política en la filosofía socrático-platónica”, Revista Latinoamericana de Filosofía, N 45 , Vol. 1, Otoño 2019,pp.33-61. E-mail: facundo.bey@gmail.com 
Yo estaba intentando hacer algo diferente en ese momento, algo que Heidegger no podía hacer en absoluto, y esto salió de mi libro, La ética dialéctica de Platón, que sirvió como mi tesis de habilitación. Intentaba llegar a la filosofía por diferentes caminos, específicamente, por el camino del conocimiento práctico. [...] el paso decisivo ya estaba dado en el hecho de que, desde ese momento, incluso si hubiera querido seguir a Heidegger, ya no podría haberme puesto de acuerdo con él

(Gadamer, 2002b, 23) 1 .

\section{Dialéctica y hermenéutica}

Aunque inicialmente dedicada al estudio del papel del placer en la ética aristotélica $(2015,383)$, motivo por el cual Hans-Georg Gadamer decidió primero realizar una introducción a la hèdoné en la ética platónica contenida en el Filebo, su tesis de habilitación comienza desde 1929 a ser reelaborada y revisada a partir de los conocimientos que el marburgués fue adquiriendo y perfeccionando en los seminarios que frecuentó desde 1928 (principalmente, los de Paul Friedländer). Esta investigación se convertirá en el primer libro del autor: Platos dialektische Ethik. Phänomenologische Interpretationen zum Philebos [La ética dialéctica de Platón. Interpretaciones fenomenológicas del Filebo] [1931].

Uno de los temas presentes, que luego tendrá gran proyección sobre los estudios posteriores de Gadamer, regresa en verdad desde el ensayo de 1928 Der aristotelische Protreptikos und die entwicklungsgeschichtliche Betrachtung der aristotelischen Ethik [El Protréptico aristotélico desde el punto de vista del tratamiento del desarrollo histórico de la ética aristotélica], aunque ahora alumbrando la figura de Platón. Se trata de la relación entre la filosofía y la política. Gadamer decide en esta ocasión partir de la Carta VII para señalar especialmente que el ideal existencial del filósofo, el de llevar una vida dedicada a la pura teoría, no es ningún sentido "extrapolítico" [ausserstaatliches], ni implica renuncia alguna a la prâxis, entendida (aunque no exclusivamente) como la preocupación por las cosas relativas a la pólis (GW 5, 5-6).

El testimonio de la Carta VII enseñaría, justamente, que la filosofía platónica deviene política en la medida que su punto de partida es, necesariamente, tanto la relación de Platón con Sócrates como la defección de la pólis ateniense con respecto a este último. En este sentido, la filosofía resulta un "desvío" [Umweg], un apartarse de los modos en los que la pólis ateniense se orienta, pero sin abandonar la marcha ni el camino. Un cambio de dirección de una importancia tal que modificará el concepto del político y de la [más] "auténtica tarea política" [echten politischen Aufgabe] para Platón, cuyo modelo será, desde entonces, la perturbadora existencia de Sócrates y sus refutaciones (GW 5, 6).

Lo anterior es de importancia capital para asumir otro de los presupuestos directrices de Gadamer en su libro y, como se ha dicho, en sus textos inmediatamente sucesivos sobre la "teoría sofística y platónica del Estado" (Gadamer, 2015, 489), tanto Plato und die Dichter [Platón y los poetas] [1934] como Platos Staat der Erziehung [El estado educacional de Platón] [1942]: "República no es un programa de reformas constitucionales entre otros,

1 Todas las traducciones de esta entrevista me pertenecen, así como las relativas a los volúmenes 5,6 y 7 de la Gesammelte Werke (GW) y los siguientes textos y entrevistas de Gadamer citados en el presente artículo: (1977), (1978), (1995), (2002b). También me pertenecen las traducciones de los siguientes textos: Sullivan (1989), Di Cesare (2003; 2007; 2015), Heidegger (GA 53; GA 97; 2009b). 
dirigido a tener un efecto político directo, sino, en cambio, un estado educacional [Staat der Erziehung]" (GW 5, 6). Y en tanto este diálogo está orientado a encontrar nuevas bases para construir un Estado genuino, cuya característica principal sería, desde luego, su función educacional, su objetivo será formar a los hombres capaces de encontrar tales bases, a partir del descubrimiento socrático de la imposibilidad de alcanzar un fundamento que no acepte preguntas, que no resista la intensidad del phármakon filosófico.

La introducción al libro sobre el Filebo a partir de la referencia a República comienza a manifestar la inseparabilidad de la pregunta por la ética y la política en el texto gadameriano, lo que a primera vista podría exigir una aclaración sobre la relación de ambos términos. En líneas muy generales, la ética constituye para Gadamer una concreta comprensión pública de la existencia dentro de la cual tiene lugar la acción humana, muy cercana a su interpretación de la noción de areté, que pareciera englobar, a su vez, lo que tradicionalmente designa el término éthos. Ahora bien, debe considerarse con atención que, en su particular lectura de Platón, la situación ética, ahora bajo la connotación del $\bar{e}$ thos o carácter (aunque no en el sentido del término kharaktér, de marca o gráphō), es el punto de partida, por medio del diálogo con otro, de la dialéctica en cuanto movimiento anímico ${ }^{2}$. En su investigación teorética del bien, la dialéctica destruiría la paz de los cementerios que instalan, por medio de la habituación, los dogmas normativos, y prodigaría una comprensión de los hombres como entes que no disponen de sí mismos de forma definitiva y cuya posibilidad más alta se encuentra siempre en la experiencia de la finitud, en el límite que no constituye obstáculo, sino posibilidad de emergencia del sí mismo como otro y de encuentro del otro con uno mismo en cuanto parcialidades múltiples de una única pólis. Es en este último sentido que la dialéctica puede ser ética y, en consecuencia, como diría Richard Sullivan, "también es política" $(1989,143)$.

Esta búsqueda que damos en llamar «ético-política», que acontece en un mismo ámbito de la existencia, de construir un Estado genuino, y su finalidad, es decir, formar ciudadanos competentes para dar dirección a la pólis de un modo tal que no sea contradictorio con la idea de Bien, está comprometida indisociablemente con el desarrollo de la areté, entendida, a un mismo tiempo, como "potencialidad e inteligibilidad existencial y específicamente humana" (GW 5,6).

Para Gadamer, en la filosofía socrático-platónica, al igual que en la socrático-aristotélica, la existencia humana en su facticidad y los conceptos de aretế y tó agathón no son tratados eo ipso sino en cuanto están determinados y son definidos en relación con una otra cosa ${ }^{3}$ que no es su opuesto ni su ausencia:

2 Gadamer tenía presente al menos ya desde 1930 la diferencia clásica entre ě $\theta$ os (éthos) y $\hat{\eta} \theta 0 \varsigma$ ( $\left.\bar{e}^{\wedge} t h o s\right)$, planteada tanto por Platón ( Leg. 792e) como por Aristóteles (EN, 1103a). Cfr. GW 5 (242).

3 En una obra posterior, "Idee und Wirklichkeit in Platos «Timaios»" [Idea y realidad en el Timeo de Platón] (GW 6, 242-270), Gadamer afirmará que: “A diferencia de República, el Filebo no se pregunta sobre la idea de Bien y su función en cuanto paradigma para la vida humana; más bien, por el contrario, se interroga sobre cómo la vida concreta de los seres humanos en toda su determinación y carácter mixto [Gemischeit], y definida como está por los impulsos y los placeres tanto como por el conocimiento y el entendimiento, puede, sin embargo, ser «buena», es decir, puede participar del Bien" (GW 6, 268). 
La pregunta socrática sobre qué cosa sea la $\operatorname{arete}^{4}$ (o una arete específica) está guiada, pues, por un concepto preliminar de arete, compartido tanto por quien es interrogado como por quien realiza las preguntas. Todo Dasein vive constantemente en una comprensión de la arete. Qué y cómo deba ser el buen ciudadano está ya dicho en una interpretación que domina toda la comprensión pública de la existencia [das ganze öffentliche Daseinsverständnis beherrschenden Auslegung, der sog]. Se trata de la así llamada moral [Moral]. El concepto de arete es, por lo tanto, un concepto "público". En él, el ser de los hombres está comprendido como un ser con-otros-enuna-comunidad [das Sein des Menschen als ein Mit-Anderen-in-einer-Gemeinschaft] (la polis) (GW 5, 39; énfasis original).

La areté está siempre presente como modo público y originario de autocomprensión y existencia. En realidad, no hay modo de ser humano por fuera de la areté, ni hombre libre que merezca ser llamado tal que no sea ciudadano: "Forma parte del ser del hombre el que éste se comprenda a sí mismo en su propia aretê" (GW 5, 39). Así como no hay extrapoliticidad para el hombre en general, no hay modo de vivir por fuera de la areté. Y no lo hay para el guerrero ni para el artesano, como tampoco para el filósofo. A esto se refería Gadamer un año antes, en su Praktisches Wissen [Saber práctico] cuando decía que "[...] Uno puede elegir su profesión. No es posible, en cambio, elegir ser un hombre, se tiene siempre que serlo. [...] Uno no puede retirarse de su existencia como hombre" (GW 5, 242).

La aretế no es algo que se pueda tener o no tener en sentido posesivo e individual. Cuando Gadamer afirma que "con la pretensión de ser un ciudadano viene dada necesariamente la pretensión aún más amplia de poseer esta arete, que hace de uno un ciudadano, es decir, un hombre" (GW 5, 40), entiende que la posibilidad de «apropiarse» de ella no es la de dirigirla o manipularla sino, en todo caso, la de acceder a la misma por medio del lógos en el que se presenta todo como tal, en su obviedad: "la pretensión" de poseer la areté refiere inequívocamente a esta participación. Este es el modo en que probablemente Gadamer recupera el dictum socrático: "La virtud no tiene amo; según se la honre o se la desprecie, cada uno tendrá mayor o menor parte de ella. La responsabilidad es de quien elige, el dios no es responsable" (Rep. 617e; trad. propia).

Cada Dasein se comprende en una areté en cuanto forma parte de una pólis, pues el comprenderse es aquello que lo define como hombre. Esta comprensión implica estar también en condiciones de dar cuenta de las acciones inmediatas que se proyectan desde aquella otra comprensión más primaria que acontece en el lógos, esa que es capaz de hacer presente lo que no aparece de ese modo. Según Gadamer, el descubrimiento de Sócrates fue que esto no sucede naturalmente y que lo que parece obvio en la comprensión media del Dasein, lo que es considerado correcto o incorrecto, exige una mediación: "la pregunta socrática sobre qué es la areté es una exigencia de un rendimiento de cuentas [Rechenschaftsgabe]" (GW 5, 40), una clarificación dialéctica de las posibilidades existenciales, "de aquello que el hombre pretende ser" (GW 5, 73). Aquí se encuentran por vez primera dialéctica y hermenéutica, como teoría y práxis existencial y común, como "arte de comprender y de hacer hablar a lo extraño y a lo que se ha vuelto extraño" (Gadamer, 1981, 92).

4 En las citas textuales aquí traducidas por el autor se mantiene la transliteración del griego utilizada por Gadamer. 
Este examen exige un trabajo de cada uno sobre sí mismo que, partiendo de las interpretaciones dominantes, dé con el para qué común del hombre y las cosas, esto es, una cierta idea del Bien que sea capaz de proporcionar una medida, una que no antecede a la comunidad, sino que es su efecto, y así dar lugar a un saber ético-político capaz de realizar un modo de vida deseable, un buen vivir (Gadamer 2001, 140; 142-143). Esa indagación de sí, del otro de uno mismo, que llega a su punto más profundo cuando se efectúa como una búsqueda común, demanda comprender el propio comportamiento en una areté determinada cada vez de cara al Bien, alcanzar con otros una justificación del deber hacer y del ser en términos del por-mor-de [Worum-willen] de la propia existencia (GW 5, 40; 44).

La voluntad socrática de entendimiento mutuo [Verständigung] es, justamente, la aceptación más radical de que la tesis propia pueda ser contradicha por otro en vistas a alcanzar un compromiso con la verdad de las cosas. No se trata de una búsqueda personal en términos de adequatio o conformidad, de reconciliación entre las palabras y las cosas, sino de un compromiso entre los hombres que supere el simple convencionalismo o la voluntad de instrumentalización (GW 5, 39).

Pero todo consenso bien podría significar la mera imitación de opiniones. Porque ponerse de acuerdo con otros no es equivalente a compartir una opinión o convenir en algo (Gadamer 2017, 465). Ponerse de acuerdo con un otro exigiría, no sólo estar de acuerdo con uno mismo, sino sostener todo posible acuerdo sólo en los límites de algo sobre lo que se va a discurrir y que no pertenece a nadie, el lógos. Empero, esto que no pertenece a nadie, que permanece en el centro, «entre» dos o más, y a partir de lo cual puede o no haber acuerdo, no resulta claro en su carácter inapropiable cuando es manipulado para impresionar al auditorio y para silenciar al interlocutor por medio de un discurso monológico, tal como sucede en el lógos sofístico (GW 5, 51-52; Gadamer 2017, 445-446; 463). Los persuasivos caminos de la mera erística (Phil. 16e-17a), así como el hedonismo absoluto «que mira a la inmediatez desde la inmediatez y para la inmediatez», pueden llevar, finalmente, sólo a un mismo lugar: la mera obtención de conformidad, la suspensión de ese diálogo con uno mismo y los otros que es el pensamiento (también GW 7, 350, 365 y Lammi 1998).

De este modo, todo auténtico diálogo se funda en una ignorancia compartida y en una necesidad compartida de saber. Para que una pólis pueda dar con su Bien (y también con su placer propio) debe partir del presupuesto de que todos los ciudadanos con-forman y com-parten, a un mismo tiempo, "una comunalidad [Gemeinsamkeit] del no-saber y una comunalidad del deber-saber, esto es, un entendimiento de la necesidad de una exigencia de conocimiento auténtica y justificada" que ponga en marcha "una búsqueda conjunta" (GW 5, 44). Porque es, efectivamente, esta última la que justifica la propia idea de saber o ciencia: "En la comunalidad de la precomprensión del Bien se basa la posibilidad última del entendimiento" (GW 5, 47).

El lenguaje no es "una simple copia del ente", un portador neutral de significados, sino fundamento de la comprensión y, por lo tanto, de la existencia humana en cuanto posibilidad más alta de ser del ente y del bíos filosófico-político (GW 5, 53; énfasis original). Para Gadamer, que da especial atención a la famosa "segunda navegación" socrática del Fedón, ser y lógos en Platón se relacionan de modo tal que, para empezar, el habla resulta un originario "tener que ver en común con algo", en el sentido de estar comprometidos con «algo» por medio de la palabra, suelo compartido de la existencia y el conocimiento (GW 
5, 23; énfasis propio). En la pólis, la "comunalidad de intereses vitales" [Die Gemeinsamkeit des Lebensinteresses] (GW 5, 53) se despliega a partir de aquella originaria precomprensión común del mundo, esto es, en la formación del lenguaje, en la cual se comprenden todos aquellos que previamente lo han acordado y pueden hacerlo de manera siempre nueva en la discusión, ya que lo que es objeto de la dialéctica es lo amphisbētēsinon, no la mera oposición entre opiniones, sino ese algo que está bajo - y a la vez conforma - el ámbito de la disputa (GW 5, 73, n. 20; 33; también Phdr. 263a.).

El mundo se encuentra - según Gadamer- precomprendido intersubjetivamente en el lenguaje (GW 5, 53). Pero ¿qué significa aquí intersubjetividad? ¿qué implica esta invocación al sujeto en este contexto? Para comenzar, es necesario aclarar que Gadamer no sugiere un regreso al modelo cognoscitivo moderno, al sujeto cartesiano. La intersubjetividad de la que habla no es la unión de dos interioridades inmediatamente dadas y cerradas sobre sí mismas, con fronteras definidas, sino un atributo del lenguaje en cuanto comprensión del mundo. El inter no es un puente entre los hombres, no es una herramienta que permite pasar de un lado al otro, un hilo por el cual una conciencia pasa a la otra, resultando, después de este pasaje, ambos «sujetos» o bien vírgenes de todo cambio después de sucedido su encuentro, idénticos a sus «puntos de vista», o bien igualados según la capacidad que uno de ellos pueda tener para absorber al otro.

Este inter de la intersubjetividad es, en cambio, en el «entre» que presupone el lógos, el lenguaje común de cuya verdad participan los «inter-locutores» y que los reúne en una comunalidad siempre y cuando se mantengan en la disposición a la conversación, en la superación permanente de los propios límites de su comprensión. "La Gemeinsamkeit - como dirá Gadamer años después en el segundo volumen de Wahrheit und Methode-, aquello que ya es tan común que no es ni lo mío ni lo tuyo, no es sino una interpretación común del mundo que hace posible la solidaridad moral y social" (GW 2, 188)

Según Gadamer, la filosofía platónica es dialéctica porque en la acción de comprender concibe desde el inicio a los hombres como entes "en camino" [Unterwegs] y "entre medio" [Zwischen] (GW 5,6), es decir, que como posibilidad más suprema y tarea del hombre reconoce su límite infranqueable de cara a su realización, su pertenencia al dominio temporal y plural: la finitud. Así, "la filosofía [...] no es ooфía, conocimiento que proporciona disposición sobre algo, sino un esfuerzo en esa dirección. En cuanto tal, es la posibilidad suprema de los hombres" (GW 5, 7).

En el terreno abierto de la cuestionabilidad la existencia y la filosofía se realizan dialécticamente. Allí entran en tensión la pretensión de conocimiento del hombre y la realidad, en su acontecer en torno a las cosas, en el espacio entre el saber y la ignorancia en el que la dóxa, como facultad intermedia [metaxú], "ase lo que erra en el medio"'6 (Rep., 478a-479d), entre el polo de la vida y de la muerte:

5 La traducción me pertenece. Considerar lo anterior es fundamental para comprender no sólo las implicancias ético-políticas de los fundamentos de la hermenéutica filosófica, sino también el sentido que adoptará para Gadamer su célebre concepto de Horizontverschmelzung, «fusión de horizontes», en Wahrheit und Mehtode (GW 1, 312, 383, 450).

6 Traducción propia a partir de la versión de Barbara Cassin y Charles Baladier $(2014,229)$. 
[...] la filosofía platónica no se limita a[l acto de] concebir tal posibilidad en cuanto la más eminente, sino que comporta el cumplimiento de esa misma posibilidad. Esto significa, sin embargo, que [el hecho de] ser humano implica que los hombres no disponen de sí mismos de forma cerrada, y que la filosofía, en cuanto posibilidad humana que tiene lugar en esta cuestionabilidad [Fraglichkeit] dialéctica, en el saberse a sí misma humana, también se realiza dialécticamente (GW 5, 7).

Donatella Di Cesare, por su parte, ha demostrado cómo este «entre», este «a través», está presente en el prefijo griego día así como la función que desempeña éste en la interpretación gadameriana de la filosofía platónica, tanto en las nociones de dialéctica, diálogo como de diaíresis, cumpliendo siempre una función de apertura bajo la forma de "la provisoriedad, la indeterminación, lo inacabado. Mientras [la dialéctica] se sabe finita, acepta la apertura infinita". En este sentido, "esta dialéctica es dialógica: su «entre» es aquel del dia-logo", que "se desarrolla ejemplarmente a lo largo del hilo conductor del lenguaje", de los lógoi (Di Cesare, 2007, 177; énfasis original). Tal como dirá Gadamer con relación a "la estructura especulativa del lenguaje" en Wahrheit und Methode, "las posibilidades finitas de la palabra están asignadas al sentido de su referencia como a una orientación hacia el infinito" (2017, 561), pues "todo hablar humano es finito en el sentido de que en él yace la infinitud de un sentido por desplegar e interpretar" (549).

Platón, al reconocer la estructura del lógos, habría dado lugar a una transformación del concepto de ser, que tuvo lugar en el Sofista: el ser es desde entonces dynamis o "posibilidad», origen de acción o de pasión (Soph. 247d8). No sólo todo lo que tiene posibilidad de actuar o padecer existe plenamente: "ser es siempre al mismo tiempo no-ser, esto es, aquello en lo cual se diferencia de todo otro, o: todo lo que no es" (GW 6, 24). La mezcla es (aunque no sólo) "del ser y del no-ser, de lo idéntico y lo diferente", una de las formas en las que se entrelazan las Ideas (GW 6,22). Por eso Gadamer sostendrá en otro texto que "La dialéctica no piensa al ser (la esencia) [das Was-sein] en el lógos, sino más bien al ser mismo como lógos" (GW 6, 28; énfasis original). Se trata de la primera indagación del marburgués sobre la construcción lingüística de "la constitución fundamentalmente finita del ser" (Gadamer, 2017, 549).

Cuando Gadamer afirmó en su primer libro que "toda unificación de lo múltiple mira a la multiplicación de lo uno" (GW 5, 33-35) era justamente porque, en su interpretación, Platón había encontrado en la diaíresis el procedimiento dicotómico que permite la superación de todo discurso, "la vuelta [Wendung] positiva de la dialéctica [...], la «euporía» después de la «aporía» (Phil. 15c)” (GW 6, 23); Di Cesare (2007, 179-180).

\section{El desvío del Dasein}

Hasta aquí, no es difícil identificar la decisiva influencia de Heidegger. Un terreno mínimo en común con el texto heideggeriano es posible ubicarlo incluso ya en el \$27 "Caracterización general de la sofística" del curso de verano de 1926, Die Grundbegriffe der antiken Philosophie [Los conceptos fundamentales de la filosofía antigua]: "En la sofística, la meditación se desplaza de la contemplación del mundo a la interpretación del Dasein, sus posibilidades de conocer y comportarse moral y políticamente" (2014, 105; GA 22, 83). En 
principio, esta caracterización de la sofística como interpretación del Dasein en sus posibilidades políticas no difiere de la tesis gadameriana aquí presentada: la areté en la que vive el Dasein, que bien puede ser la areté sofística, domina la comprensión de las acciones de los miembros de una comunidad.

Por otro lado, la definición de aretế de Gadamer no puede dejar de ser confrontada con el \$27 de Sein und Zeit, en el que "la publicidad" ["die Öffentlichkeit”] reúne los modos de ser del uno [das Man] (distancialidad, medianía y nivelación), regula la interpretación del mundo y del Dasein (2009a, 147; GA 2, 127). Su fuerza está, justamente, en que toda cosa por medio de ella se presenta como evidente, pero es precisamente esa claridad la que oscurece el carácter encubierto de lo que se muestra como disponible y sabido en la compartida cotidianidad. En resumen, siguiendo a Gadamer, la areté socrático-platónica reuniría, en los términos de Heidegger, el carácter de la Auslegung y la Öffentlichkeit, de la interpretación y la publicidad.

Igual de trivial que rechazar la explícita influencia de Heidegger sobre Gadamer (GW 5, 159) sería hacer pasar el pensamiento de un autor por el del otro. Desde luego, no es posible proporcionar aquí un análisis detallado y preciso de todos los puntos de contacto entre ambos autores, ni siquiera de aquellos en los que Aristóteles y Platón conforman su centro, pero eso no significa dejar de lado ciertas modulaciones particulares que hacen a una divergencia más general y relevante, reconocida incluso por el propio Gadamer.

Las formulaciones de este último no se limitan a replicar las aserciones de Heidegger ni las trasladan al horizonte de la antigüedad. Esto puede advertirse, por ejemplo, en que si bien Gadamer reconoce que en el discurso, particularmente en la confirmación por parte de otro que supone el consenso, tienen lugar formas insustanciales, caídas o impropias (GW 5, 33) (asimilables a aquel movimiento inconducente que el Sócrates platónico identifica como adoleschía en Teeteto, es decir, la charlatanería; Tht. 195b-c) no hay, en cambio, en su propuesta de lectura sobre el paso del diálogo socrático a la dialéctica platónica (y luego a la apodíctica aristotélica), ninguna posibilidad solipsista de dar con lo propio ni tampoco renuncia alguna a la caracterización del Dasein como zōon lógon échon. Análogamente la fenomenología de las emociones o afectos que realiza Gadamer en su libro sobre el Filebo, diversa de la de Sein und Zeit, si bien afirma que el dolor implica una turbación, es decir, una interrupción de la distracción recreativa, que posibilita una temporalidad en la que la reapropiación de la existencia puede tomar lugar que "crea una morada [Aufenthalt] en la que su constante pesantez se le torna tangible" al Dasein (GW 5, 129-130), sin embargo, la misma no sería suficiente para que el Dasein se encamine hacia el conocimiento de sí, sino que demostraría solamente el estatuto mixto de un placer que se funda en la negación del sufrimiento y de lo que sería su contracara: un dolor intenso, pero, también éste, aporético: "[...] cuando sufre un dolor, también el Dasein está especialmente ansioso de buscar olvidarse a sí mismo en el disfrute, y precisamente los placeres más intensos - sobre todo aquellos corporales - tienen este carácter de entumecimiento" (GW 5, 130; énfasis original). Gadamer asumía así que el placer puro para Platón no tiene el carácter de la privación satisfecha, sino del imprevisto [der Plötzlich] (Rep. 584e; Phaed. 258e3). El placer se da en el desvelamiento del ser en su mera presencia. No hay posibilidad del género de vida más alto, de «felicidad» en sentido eminente, sin una justa mezcla entre hêdoné y phrónēsis: "el Dasein se comprende en su posibilidad suprema: como cognoscente", es decir, como cues- 
tionador. "El placer y el disfrute - concluye Gadamer - le caben en cuanto están insertos en esta orientación hacia su posibilidad suprema" (GW 5, 155).

En cierto modo, el diálogo que Gadamer planteó a Heidegger pertenece a la misma clase del diálogo socrático. No tenía como objetivo la persuasión por sí misma ni tampoco la simple empatía o imitación. Proponía, en su lugar, un desvío de y desde la analítica del Dasein, un despegue posibilitado por el abandono de "la lectura de Platón como precursor de la ontoteología" (Gadamer, 2015, 19). Esa virada, que lícitamente puede evocar para el lector la auténtica tarea que tiene la filosofía a partir del Platón político, significó para Gadamer "una auténtica desviación del pensamiento heideggeriano [einer echten Abweichung von Heideggers Denken]" (2015, 19; GW 2, 12)7. Gadamer se propuso entonces algo que Heidegger jamás buscó: “[...] hacer hablar a los diálogos platónicos que están permeados de una tonalidad musical distinta [a la del Aristóteles no escolástico]” (2002a, 141).

Más allá de los puntos de contacto entre la filosofía de Gadamer de este período y el pensamiento de Heidegger - por ejemplo, la idea de que la " $\pi \alpha \iota \delta \varepsilon i ́ \alpha$ no es formación" sino cognada existencial de la alétheia, sinónimo de he hemetéra phýsis, de la esencia intermedia del hombre, en constante e irreductible confrontación con la apaideusia, que capacita al hombre para filosofar, esto es, ser libre (GA 34, 114-115) - nadie podrá encontrar en el último una reflexión sobre la pólis y la política del modo en que el primero lo aborda en sus tempranas obras y en el preciso momento en que lo hace y, por qué no destacarlo, en el que deja de hacerlo: en medio de la crisis social, política y cultural de la República de Weimar que vio nacer y llegar al poder al nacionalsocialismo.

Tómese en cuenta un ejemplo que no carece de dificultades: si bien la definición de Gadamer de pólis como "el ser de los hombres en cuanto ser-con-otros-en-una-comunidad" (GW 5, 39) parece de innegable influencia heideggeriana, en particular con relación al §74 de Sein und Zeit en el que Heidegger hace declinar el Mitsein [ser-con] como Mitgeschehen [co-acontecer] de una "Gemeinschaft, des Volkes" [comunidad, del pueblo] (GA 2, 383), es imposible no preguntarse por qué Gadamer desvía el sentido del Dasein heideggeriano tan temprano en su propia obra, cómo lo hace y cómo lo seguirá haciendo en los años siguientes por medio de la interpretación de Platón.

¿Por qué no tomó Gadamer entonces el heideggeriano callejón sin salida de la negación de lo político en nombre del origen de lo político (Lacoue-Labarthe, 2002, 27, 29; 2007, 98; 2010, 158), en el que, en síntesis, la pólis cuando no terminó significando Staatsgemeinschaft, "Estado como comunidad", "a la que el ser humano puede y debe dar forma",

7 "Llego así al punto de la auténtica desviación respecto al pensamiento de Heidegger, al que dedico buena parte de mi trabajo y especialmente de mis estudios sobre Platón” (Gadamer, 2015, 19). Esta desviación tendrá, en buena parte, como célebre corolario a la hermenéutica filosófica de Wahrheit und Methode: "Los estímulos filosóficos que recibí de Heidegger me llevaron cada vez más al dominio de la dialéctica, tanto de Platón como de Hegel. Dediqué décadas de enseñanza a elaborar y probar lo que he llamado aquí el efecto unitario platónicoaristotélico. Pero en el fondo estaba el continuo desafío que me había planteado el camino que tomó el propio pensamiento de Heidegger, y especialmente su interpretación de Platón como el paso decisivo hacia el olvido del Ser del «pensamiento metafísico». Mi elaboración y proyección de una hermenéutica filosófica en Wahrheit und Methode da testimonio de mis esfuerzos para resistir teóricamente este desafío" (GW 7, 130). Antes, el 5 de abril de 1961, Gadamer le había enviado a Leo Strauss una carta en la que le aseguraba "Mi punto de partida no es el olvido del ser, «la noche del ser», sino, en cambio - esto lo digo tanto en contra de Heidegger así como de Buber - la irrealidad de esa afirmación" (Gadamer, 1978, 8). 
como nación, como pueblo que se decide por el Estado (GA 38, 75-77; 2018, 67-70), en el seno de una misión historial [geschichtlichen] y espiritual (GA 16, 107-117), terminó por querer decir estrictamente historicidad (1999b, 140-141)? ¿Por qué partiendo de una caracterización de lo político como posibilidad fundamental de los hombres, que pocos años después sería compartida abiertamente por Heidegger - y más tarde renegada en función de la incompatibilidad metafísica entre el acontecimiento de la pólis y la pertenencia al ámbito de la maquinación [Machenschaft] de la política (1999b, 64; GA 96, 53) - , Gadamer se apartó del camino filosófico y político que lo hubiera podido llevar, como a su maestro, a identificar alternativamente al ser con "la historia de un pueblo" (GA 34, 145), al pueblo con el ente y al Estado con el ser (Heidegger, 2018, 74), reclamando, para su mutua e inseparable realización, la necesidad, por un lado, de la voluntad efectiva, operativa, realizadora, de un Führer, de un hombre con prioridad ontológica sobre otros, al cual el pueblo - esos "otros" que él habría creado y transformado en seguidores, de entre los cuales surgirá la comunidad $(2009 b, 87)$ - se sacrificara con fidelidad en la lucha y, por otro lado, de una "nobleza política" que custodiara la tradición (2018, 71-72, 78, 80, 92-93)? ¿Por qué plantear, en su lugar, un ideal existencial del filósofo y político como ciudadano, como alguien que no renuncia en modo alguno a la preocupación por las cosas relativas a la pólis ni se desembaraza de la pasión que urde el hilo polémico de la filosofía, su severa mirada intransigente hacia el presente y el pasado?

Un esbozo de respuesta, aunque muy simple, podría ser el siguiente: Sócrates, que no era un profesor de filosofía ni un político profesional, sino un filósofo - en el mismo sentido que Pitágoras dijo serlo ante León, según cuentan Diógenes (I, 12) y Cicerón (Disp. Tusc., V.37.8) - , planteó el problema de la vida justa y de la vida reflexiva para todos los hombres. Gadamer planteó el sentido político de la filosofía a partir de Platón del mismo modo: no se trata de tener una competencia particular que pueda ofrecer respuestas para abordar los problemas de la vida en común, de que los filósofos profesionales sean los más aptos para dirigir directamente al Estado o espiritualmente a su dirigencia. Cualquier interpretación que vaya en este sentido confunde el saber, el conocimiento, la ciencia, con la experticia y, por lo tanto, reduce a Platón a un apologeta de aquello que en nuestro tiempo denominamos «tecnocracia», o gobierno de los así llamados «especialistas». Al mismo tiempo, esto no significa que se deba encontrar un particular hombre excepcional, un líder, a razón de "la forma impresa de su ser" [der geprägten Form seines Seins] (Heidegger, 2009b, 73). En cambio, se trata de que los hombres, cada uno de ellos, sean capaces de orientar, por medio del razonamiento y el diálogo, las preguntas capaces de cuestionar los errores dogmáticos de la comunidad en la que se encuentran existencialmente ya comprendidos y que se yergue sobre unos determinados hábitos y valores (éthos). En cuanto ciudadano, el filósofo no puede ni debe eximirse de la responsabilidad que tiene consigo mismo, con respecto a un tú y a un nosotros. Por ese mismo motivo los modelos paradigmáticos o figuras de la ética-política dialógico-dialéctica de Gadamer no pueden ser las figuras [Gestalt] definidas de Sócrates ni de Platón, cada una afincada cómodamente en un reportorio de dogmas, sino, más bien, el «en medio» entre el Sócrates platónico y el Platón socrático (GW 5, 5).

Pensar la pólis, que no es una cosa, es pensar al Dasein. La pólis no es sino el modo de ser del hombre "mundano". En esto seguramente acordarían tanto Gadamer (GW 5, 18) como Heidegger, aunque para el primero la pólis no sea una instancia, al decir de 
Lacoue-Labarthe, "archi-política" (2010, 176, 181), ni la comunidad, como pueblo, su esencia. Para el filósofo de la fusión de horizontes la filosofía no podía sino fundarse en una horizontalidad fundamental.

Con el fin de entender aún mejor la particularidad y originalidad del trabajo de Gadamer, resulta de suma importancia reponer aquí algunos de los argumentos esgrimidos en aquellos mismos años por Heidegger en su seminario Einleitung in die Philosophie [Introducción a la filosofía $]^{8}$.

La figura sobre la que nos detendremos aquí por un momento, el Miteinandersein o serunos-con-otros, había sido ya introducida por Heidegger a partir del $\$ 26$ de Sein und Zeit. Pero, como reconoció Francisco González (2009, 63), en el contexto del curso de 1928/29 su tratamiento resulta más rico. Heidegger inicia el $\S 13$ regresando sobre un argumento manido para el lector de su libro más conocido: los entes que tienen nuestra forma de ser no son otros Dasein delante «cabe» nosotros, sino ahí «con» nosotros. El Dasein es, respecto a sí, Mit-dasein, determinado y definido "por un con-ser, por un Mit-sein con los otros" (1999a, 93), para el cual el «con» debe ser entendido como participación [Teilnahme] y como denotando comunalidad [Gemeinsamkeit], un carácter común [Gemeinschaftliche], esto es, que de varios "(pero en común) puede decirse (o vale) algo igual" (94-98). ${ }^{9}$ Eso igual no es ni la conducta externa, ni aquello respecto a lo que nos comportamos, sino más bien "una intención dirigida a lo mismo, puesta en lo mismo, el estar ocupado con vistas a lo mismo", un "haberse de varios acerca de lo mismo", que, en tanto idéntico, "no excluye el cambio y tampoco la diferencia", sino todo lo contrario (100-103). En este caso, la mismidad [Selbigkeit] de lo mismo se da como tal porque "puede ser aprehendido por varios" (106). Esta mismidad no es sino la comunalidad de la cosa para varios, la cosa y nuestro ser cabe ella (109). A su vez, esa comunalidad no se da en el uso que se hace o se puede hacer de la cosa sino en el compartir [teilen] algo, lo que significa "dejarse mutuamente algo para el uso y en el uso", ya que para poder dejarnos mutuamente lo común, nuestro ser cabe lo común (si se me permite) implica un previo y originario dejar-ser [Sein-lassen] que lo posibilite, una cierta indiferencia [Gleich-gültigkeit] subyacente respecto a las cosas que les permita aparecer como en lo que en cada caso son (111-112). Pero lo que nos compartimos no son los entes que están-ahí-delante, las cosas, sino su des-ocultamiento, es decir, la verdad que les con-viene: "lo común es la verdad del ente" (114), "el ser-unos-con-otros es un compartir la verdad" y esta última un "ingrediente constitutivo de la estructura del ser-unos-con-otros" como forma del Dasein $(115,118)$.

8 No comparto la tesis de Vigo sobre que si bien el curso de 1928/29 "no se orienta fundamentalmente a partir de la consideración de estructuras dialógicas" [...] "sin embargo, incluye como uno de sus objetivos básicos la puesta de manifiesto de condiciones estructurales que dan cuenta de la posibilidad de todo diálogo genuino, tal como dichas condiciones han sido relevadas posteriormente por concepciones de orientación esencialmente dialógica" (2008, 262). Todo ello, considero, no logra cerrar el hiato que intento resaltar, así como sus implicancias políticas, entre las filosofías de Gadamer y Heidegger, entre la ontología del Dasein y la estructura dialógica de la comprensión, ya sea en esos años o en los venideros.

9 La traducción de Manuel Jiménez Redondo, que he utilizado hasta aquí, traduce Gemeinsamkeit por comunidad. Si bien no es posible afirmar que es del todo incorrecto, en el contexto específico del curso de referencia, resulta problemático ya que, en forma explícita, Heidegger hará uso del término Gemeinschaft, para el cual no existe otra traducción posible. 
El ser-uno-con-otros no equivale al ser-ahí-fácticamente-con-otros, pues la Existenz puede existir sola sin dejar de implicar el ser-unos-con-otros (126-127). Tampoco es un yo que encuentra un tú, una existencia encapsulada junto a otra, proveniente de una fórmula "altruista", que introduce "una especie de solipsismo en pareja" (131). Y, sin embargo, un sujeto sumido, enfrascado sin reflexión alguna, vuelve posible, paradojalmente, la comunidad [Gemeinschaft].

En principio, se podría objetar, no hay lugar para paradoja alguna: Heidegger intenta mostrar la estructura del Dasein y el modo en que la comunidad se yergue sobre la base del unos-con-otros [Miteinander]. De hecho, no se trata aquí de querer señalar contradicción de ningún tipo. En cambio, se busca evidenciar una diferencia sustancial entre su ontología del Dasein y la filosofía dialógica de Gadamer. Si para Heidegger la relación yo-tú presupone su previa determinación por el unos-con-otros, es porque la comunidad está siempre presupuesta, y la reflexión sobre ella misma no da lugar a nada esencial a la comunidad. Con otras palabras, la comunidad está liberada de la reflexión y la experiencia de la finitud queda encerrada en el destino histórico de la facticidad del Dasein, encaminado hacia la reapropiación de sí mismo. En sus propios términos: el yo no "irrumpe en el otro" (157).

\section{Conclusiones: el choque del Dasein}

Para el filósofo del inicio el otro no da inicio a nada. Y si bien uno podría decir que el hecho de que la política para Heidegger no sea necesaria para «que haya» comunidad pareciera dejar a la primera como reserva de un ámbito de plena libertad, en realidad, y en vista del contraste que se pretende enfatizar aquí, debería señalarse que una pólis «liberada» de la reflexión y, sobre todo, de la reflexión sobre sí misma, así como un Dasein liberado de la irrupción del otro, hace de la política algo innecesario, banal.

En una entrevista entre 1999 y 2000 con Ricardo Dottori, Gadamer dejó en claro su posición al afirmar inequívocamente que "El Mit-sein se vuelve realmente sostenible sólo con otro" (Gadamer, 2002b, 26). A diferencia de Heidegger, Gadamer reconoció entonces haber "desarrollado gradualmente" al interior de su obra filosófica no el Mit-sein, al que consideraba, en el terreno de la analítica heideggeriana, una vana concesión inconsecuente, sino el Miteinander (26). Un Mit-sein que está supuesto, dado por sentado, es la contracara de un otro debilitado, indiferenciado, repetible, superfluo, una existencia conjunta falseada que se agota en un "«dejar que los otros sean» ['Den anderen sein lassen']" que no logra despertar "un auténtico «estar-interesado-en-ellos» [Ihm-zugewandt-sein]" (26).

El verdadero dejar-ser al otro y a lo otro que señala Gadamer no puede ser sinónimo de una indiferencia originaria sino de "un dejarse determinar por el encuentro mismo" (1977, 65), aquello que imprevisiblemente surgirá a partir del choque con un tú, con una época, una obra de arte o un texto: el encuentro tiene para Gadamer la fuerza del verdadero inicio que, paradójicamente, abre éticamente el significado de la finitud, deja que lo que era sea, pero no encerrado sobre sí mismo, sino para aquel que particularmente uno está siendo y que no puede dejar de ser, en vistas de la superación de los límites personales que franquean toda comprensión: "sólo el individuo tiene un tú" (Gadamer, 1995, 39).

El desamparo que implica esta forma de entender el dejar-ser resulta tanto en un abandono humano recíproco, así como una deserción de la filosofía y su tarea; pavimenta el 
camino del aislamiento, la autoalienación, la enemistad radical del hombre contra sí mismo y la ignorancia de la situación hermenéutica existencial (1983, 123-138). No por azar, en la entrevista antes mencionada, concluye Gadamer que aquello que había intentado sin éxito demostrarle a Heidegger en los años '20 había sido que

Precisamente en nuestra relación ética con el otro, nos queda claro lo difícil que es hacer justicia a las demandas del otro o incluso simplemente tomar conciencia de ellas. La única forma sabia de no sucumbir a nuestra finitud es abrirse al otro, escuchar al "tú" que está frente a nosotros (2002b, 33) (Cfr. también Di Cesare 2015, 112).

Si el interés de Gadamer por la dialéctica (tanto platónica como hegeliana) ya había mostrado un temprano esbozo de polémica con su maestro, podría agregarse que este alejamiento se acentuó al preguntarse en qué sentido la dialéctica platónica es (o puede ser) ética (GW 5,158 ). Este cuestionamiento Heidegger no se lo planteó, aunque había sentado las bases en 1929 para pensarlo - como reconoce Trabattoni (2009, 133-134) - en un pasaje de Vom Wesen des Grundes (GA 9) [La esencia del fundamento], al tratar de vincular, por medio de Platón (Rep. 509b), el agathón, en cuanto aitía (causa teleológica), con la trascendencia del Dasein y su capacidad de proyectarse:

Pero ¿se puede interpretar el $\dot{\alpha} \gamma \alpha \theta$ òv como trascendencia del Dasein? [...] El problema del $\alpha \gamma \alpha \theta$ òv sólo es el punto culminante de la pregunta central y concreta por la posibilidad fundamental de la existencia del Dasein en la "polis". [...] en cuanto proyecto que desvela el ser, dicha comprensión es la acción originaria de la existencia humana, en la que todo existir tiene que estar arraigado en medio de lo ente. Así pues, el $\dot{\alpha} \gamma \alpha \theta$ òv es esa $\check{\varepsilon} \xi ı \varsigma$ (potencia) que es dueña de la posibilidad (en el sentido de la posibilitación) de la verdad, la comprensión e incluso el ser, y además de los tres a la vez en su unidad (2001, 137-138; énfasis original).

Lo anterior, podría objetarse, se encuentra en consonancia con la caracterización gadameriana en Platos dialektische Ethik del Bien como Worumwillen del ser del hombre y como prerrequisito de la comprensión, equivalente a la aretế. En el texto gadameriano, el Bien no puede ser un conocimiento que sólo tienen algunos, "por medio del cual sólo los «sabios» se distinguen" sino que, en cuanto la "pretensión de este conocimiento constituye la esencia de la existencia humana", [...] "todos deben pretender tener[lo] y, por lo tanto, buscarlo continuamente en la medida en que no lo tengan" (GW 5, 39) (Cfr. también Gadamer $1981,83-93 ; 2016,160)$.

El sentido del Worumwillen gadameriano se explica, notablemente, en el contexto de la primera aparición de la noción de Spiel [juego] en la obra de Gadamer, entendido como modo de la existencia presente y compartida en una actividad cuyo objeto está supeditado al propio "pormor-de[l]" (juego) (GW 5, 25). Esta noción operativa de Spiel y del Worumwillen constituirían la clave de lectura de Gadamer para interpelar la comprensión y el cuidado de sí en función del agathón tanto en Platón como en Aristóteles (GW 5, 40,44, 58), la condición de la autocomprensión del Dasein en una aretế determinada, cada vez de cara al Bien y en vista de una acción situada. Como Heidegger (GA 22), Gadamer rechazaba la identificación moderna, impulsada 
por Rudolf H. Lotze (1817-1881), entre el agathón y el valer, una idea de Bien como ámbito formal del valer objetivo de los valores $(1843,7)$, de la economía moral y la obligación de los hechos, que reforzaría la concepción dualista del chorismós. Sin embargo, al rechazar el marburgués esta apropiación neokantiana de Platón, no buscaría mostrar la superioridad de la ontología aristotélica frente a la platónica sino su raíz común en el lógos y el modo pleno de participación de los hombres en la aretée, ligado a un saber (Meno. 89a), que no es ni técnico ni teórico: es una razonabilidad práctica, que tampoco es un instrumento ni una facultad sino una disposición existencial orientada al tó agathón (GW 5, 246).

Pero las diferencias entre las tesis de Heidegger y Gadamer son ostensibles e insalvables. Heidegger planteó, sin ambigüedad alguna, en su seminario del semestre de invierno de 1931/32, Vom Wesen der Wahrheit. Zu Platons Höhlengleichnis und Theätet [La esencia de la verdad. Sobre la parábola de la caverna y el Teeteto de Platón] (GA 34), que la Idea del Bien platónica no puede representar "algo ético o moral" $(2007,101)$ (ni lógico ni gnoseológico), sino tan sólo el posibilitamiento del ser y del no-ocultamiento. Desde entonces, las nociones heideggerianas de ética y pólis serán indisociables (no sucederá lo mismo con la relación entre pólis y los conceptos de político y política), aunque de un modo absolutamente distinto que para Gadamer.

Así como en 1935 la pólis heideggeriana se resumía en el Da del Dasein, "el lugar de la historia" (Heidegger: 1999b, 140-141), en el semestre estival de 1942, para un Heidegger cada vez menos entusiasta con respecto al nacionalsocialismo (GA 96, 43), devenía "el sitio de la morada [Aufenthalt] de los hombres en cuanto históricos[,] en medio de los entes" (GA 53, 108). Diversamente de lo que había planteado en el seminario de 1933/34, ahora la pólis no es sinónimo de Staatsgemeinschaft, ni el deber del ente-pueblo-nación es decidirse por el ser-Estado (GA 38, 75-77): "la лó лó $\lambda ı \varsigma$, precisamente ella, no es, por lo tanto, un concepto «político»" (GA 53, 99). Incluso en los Schwarze Hefte [Cuadernos negros] de 1939-1941 Heidegger dirá "La política no tiene más nada que ver con la $\pi$ ó $\lambda$ ıs, ni con la moral, ni mucho menos con «devenir un pueblo» [Volkwerdung]" (GA 96, 43). Esto último es fundamental para entender que, más allá de las variopintas modulaciones de la pólis heideggeriana de las décadas del 1930 y 1940, la afirmación que aparece en los Schwarze Hefte del período sucesivo (1942-1948), refleja lo que, en última instancia, permanece desde Sein und Zeit: "Piden una «ética» y no ven que la temida «teoría» aún está aquí. Se cree que la filosofía sólo es verdadera «filosofía» si se torna «popular». «Ética» es la «técnica» de las normas; son inexpertos en el $\hat{\eta} \theta 0 \varsigma$ " (GA 97, 86).

No son las lecciones de Aristóteles sobre "ética", sino las tragedias del poeta Sófocles (fundamentalmente Antígona) las que, para el filósofo de Meßkirch, dicen este morar (2001, 289-291), así como será la interpretación de la sentencia del fr. B119 de Heráclito la que habilite en la célebre Brief über den "Humanismus" [Carta sobre el "Humanismo"] de 1946, una definición del $\bar{e}^{\wedge} t h o s$, como antes de la pólis, que termina en Aufenthalt, "morada", "estancia"10.

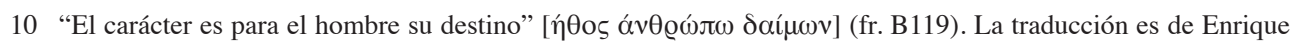
Hülsz Piccone $(2011,268)$. La interpretación heideggeriana, que sustituye carácter por morada, es discutida especialmente por el autor mexicano y descartada por implausible (268, n. 59; 2009). 
Pero el habitar de la "ética originaria" no da lugar al hombre, sino a la ontología. La ética heideggeriana, es cierto, se sustrae del dominio de las normas, de lo que Hartmann llamaba en 1926 la tiranía de los valores $(1935,524)$, pero se detiene ante la verdad del ser y allí se demora solitariamente. Más allá del impulso que le ha intentado dar Jean-Luc Nancy ${ }^{11}$, la Aufenthalt, en paralelo a lo que sucede con la política, resulta una suerte de archi-ética, una nueva negación en nombre del origen mismo del origen. Trágicamente, es también un modo de concebir la vida en común. Nada de lo que supone esta lectura de Heidegger puede encontrarse en la textualidad de Gadamer ni en su interpretación ético-política de Platón que, por otra parte, le precede.

El carácter posibilitador del agathón en la filosofía gadameriana no descuida, sino que intensifica su fuerza ético-política, que no renuncia en momento alguno a su matriz socrático-platónica y a una nueva interrogación y valoración de la ética y la dialéctica. Aunque Fred Dallmayr lo haya dicho con respecto a Plato und die Dichter y Platos Staat der Erziehung, cabe aquí reponer su señalamiento de que ya en estos primeros textos "la aproximación de Gadamer [...] tiene el carácter de una hermenéutica política o político-moral (a diferencia de la variante filosófica ontológica)" (1990, 93), es decir, la de Heidegger.

Para Gadamer, como indica con claridad Di Cesare, "[...] la experiencia de la finitud es el choque [l'urto] del Dasein en el límite que, dejando emerger la excentricidad destinal, lo empuja a salir de sí, en el más allá que es siempre el infinito más allá del otro" (2007, 30; 2003, 295). Ese choque [Anstoß], es un encuentro [Begegnung] que determina "cómo se deja que lo que era sea para aquel que se es" (GW 8, 139). Así, el Seinlassen gadameriano, podría decirse, se actualiza como Sprechenlassen: reconoce la Andersheit, deja hablar a lo otro, pero no incondicionalmente: debe esa otredad decir algo para uno, siempre de nuevo (GW 1, 367). Para el marburgués, el acuerdo, el compromiso de ponerse bajo la verdad del lenguaje, reúne a los hombres, pero no los amontona ni los aísla, sino que los transforma, les procura la posibilidad de darse una identidad en la participación, cambiando continuamente ya que, como dirá muchos años después "todas las comunidades vivas son comunidades de lenguaje, y el lenguaje sólo existe en el diálogo" $(1995,36)$. El acuerdo implicado en el diálogo, es decir, "la disposición para el diálogo" [Gesprächsbereitschaft], "[...] es sólo la entrada en este juego [del lenguaje], no el intento sin sentido para mantenerlo dentro de unos límites" (1995, 53). La comprensión en el acuerdo nunca agota a los interlocutores ni a la cosa en torno a la cual dialogan ni tampoco disuelve la diferencia en la identidad. "Si se dice que hay acuerdo sobre algo, ello no significa que el uno se identifique persuasivamente con el otro. Uno con-viene [Man kommt überein], tal como nuestro lenguaje lo expresa bellamente. Es una forma superior de syntheke, para ofrecer el genio de la lengua griega" (GW 2,16). Como explica en su célebre Wahrheit und Methode, el diálogo no es sino "una transformación hacia lo común donde ya no se sigue siendo el que se era" (Gadamer 2017, 458). Así, “el diálogo con el otro, sus objeciones o su aprobación, su comprensión y también sus malentendidos son una especie de expansión de nuestra individualidad y una piedra de toque de la posible comunalidad a la que la razón nos alienta" (GW 2, 210).

En estos primeros trabajos de fines de los años '20 y comienzos de la década siguiente, como en los textos venideros sobre filosofía política platónica, Gadamer hizo suya la orien-

11 Sigo aquí las referencias de Di Cesare sobre Nancy $(2001 ; 2005)$. 
tación fenomenológica y, aunque abierto a las influencias de sus grandes maestros, sobre todo en términos metodológicos, evitó en lo fundamental la imitación de sus interpretaciones y conclusiones. Con la mirada dirigida intencionalmente a la phýsis, a la pólis misma, Gadamer respondió a la solicitud de una "auténtica política filosófica" (GW 5, 175), haciendo honor a su temprana interpretación del Protréptico aristotélico, tanto como fenomenólogo de lo político como en su original interpretación de Platón. Asimismo, innegable es la resistencia a su destrucción de lo común, del «entre», en su vocación filosófica, en peligro tanto ante la apatía e instrumentalismo del individualismo posesivo como de la apropiación ideológica totalitaria de Platón a través de fórmulas völkisch. De este modo, el Dasein gadameriano queda tempranamente a salvo del fuego que cruza Sein und Zeit entre, por un lado, la propiedad del pueblo y de la muerte en singular y, por el otro lado, de la impropiedad del das Man.

\section{Referencias}

Cassin, B. y Baladier, C. (2014), Dictionary of Untranslatables. A Philosophical Lexicon, Steven Rendall, Christian Hubert, Jeffrey Mehlman, Nathanael Stein, Michael Syrotinski (trads.), Princeton-Oxford: Princeton University Press.

Dallmayr, F. (1990), "Hermeneutics as Justice", en Festivals of Interpretation: Essays on Hans-Georg Gadamer's Work, Kathleen Wright (ed.), Albany, NY: State University of New York Press, 90-110.

Di Cesare, D. (2003), Utopia del comprendere, Genova: Il Nuovo Melangolo.

Di Cesare, D. (2007), Gadamer, Bologna: Il Mulino.

Di Cesare, D. (2014), Heidegger e gli ebrei. I "Quaderni neri”, Torino: Bollati Boringhieri.

Gadamer, H.-G. (1977), Die Aktualität des Schönen, Stuttgart: Reclam.

Gadamer, H.-G. (1978), "Correspondence Concerning Wahrheit und Methode: Leo Strauss and Hans-Georg Gadamer", en The Independent Journal of Philosophy 2: 5-12.

Gadamer, H.-G. (1981), La razón en la época de la ciencia, Barcelona: Alfa.

Gadamer, H.-G. (1983), Lob der Theorie. Reden und Aufsätze, Frankfurt a. M.: Surkhamp.

Gadamer, H.-G. (1995), Hans-Georg Gadamer im Gespräch. Hermeneutik, Ästhetik, praktische Philosophie, Carsten Dutt (ed.), Heidelberg: Universitätsverlag C. Winter.

Gadamer, H.-G. (2001), Antología, Salamanca: Sígueme.

Gadamer, H.-G. (2002a), "Los griegos, nuestros maestros". Una entrevista con Glenn W. Most, trad. de Dissinger L., Dagmar, Praxis Filosófica No. 14.

Gadamer, H.-G. (2002b), Die Lektion des Jahrhunderts: ein Interview von Ricardo Dottori, Vol. Wissenschaftliche Paperbacks, Münster: LIT.

Gadamer, H.-G. (2015), Verdad y método II, trad. Manuel Olasagasti Salamanca: Sígueme.

Gadamer, H.-G. (2016), El movimiento fenomenológico, Madrid: Síntesis.

Gadamer, H.-G. (2017), Verdad y Método I. Fundamentos de una hermenéutica filosófica. Trads. Ana Agud de Aparicio y Rafael de Agapito, Salamanca: Sígueme.

Gadamer, H.-G. GW Hans-Georg Gadamer, Gesammelte Werke, Mohr Siebeck, Tübingen, 1985-1995.

Gadamer, H.-G. (GW 1), Hermeneutik 1 (Wahrheit und Methode. Grundzüge einer philosophischen Hermeneutik), 1986. 
Gadamer, H.-G. (GW 2), Hermeneutik 2 (Wahrheit und Methode [II]: Ergänzungen. Register), 1986.

Gadamer, H.-G. (GW 5), Griechische philosophie I, 1985.

Gadamer, H.-G. (GW 6), Griechische Philosophie II, 1985.

Gadamer, H.-G. (GW 7), Griechische Philosophie III (Plato im Dialog), 1991.

Gadamer, H.-G. (GW 8), Ästhetik und Poetik I (Kunst als Aussage), 1993.

González, F. J. (2009), Plato and Heidegger: A Question of Dialogue, University Park.

Hartmann, N. (1935), Ethik, Berlín, Leipzig: De Gruyter.

Heidegger, M. (2009b), “Über Wesen und Begriff von Natur, Geschichte und Staat”. Übung aus dem Wintersemester 1933/34, en Denker, A., Zaborowski, H., Heidegger und der Nationalsozialismus. Dokumente. Freiburg: Karl Alber [Naturaleza, Historia, Estado, trad. Jesús Escudero, Madrid: Editorial Trotta, 2018].

Heidegger, M. (GA 2), Sein und Zeit, Tubingen: M. Niemeyer, 1986 [Ser y tiempo, trad. Jorge Eduardo Rivera, Madrid: Trotta, 2009a)].

Heidegger, M. (GA 9), Wegmarken (1919-1961), F.-W. von Herrmann (ed.), 1976 [Hitos, trads. A. Leyte y H. Cortés, Madrid: Alianza, 2001].

Heidegger, M. (GA 16), "Die Selbstbehauptung der deutschen Universität”, en F.-W. von Herrmann (ed.) Reden und andere Zeugnisse eines Lebensweges. Frankfurt am Main: Klostermann, 2000.

Heidegger, M. (GA 22), Grundbegriffe der antiken Philosophie (SS 1926), Franz-Karl Blust (ed.), 1993 [Conceptos fundamentales de la filosofía antigua, Buenos Aires: Waldhuter, 2014].

Heidegger, M. (GA 27), Einleitung in die Philosophie (WS 1928/29), Otto Saame e Ina Saame-Speidel (eds.), Frankfurt am Main: Vittorio Klostermann, 1996 [Introducción a la filosofía, trad. Manuel Jiménez Arredondo, Madrid: Frónesis-Ediciones Cátedra, 1999a].

Heidegger, M. (GA 34), Vom Wesen der Wahrheit. Zu Platons Höhlengleichnis und Theätet (WS 1931/32), Hermann Mörchen (ed.), 1988 [De la esencia de la verdad. Sobre la parábola de la caverna y el Teeteto de Platón. Lecciones del semestre de invierno de 1931/32 en la Universidad de Friburgo, trad. Alberto Ciria, Barcelona: Herder, 2007].

Heidegger, M. (GA 38), Logik als die Frage nach dem Wesen der Sprache (SS 1934), Günter Seubold (ed.), Frankfurt: Vittorio Klostermann, 1998.

Heidegger, M. (GA 40), Einführung in die Metaphysik (SS 1935), Petra Jaeger (ed.), 1983 [Introducción a la metafísica, trad. Ángela Ackermann Pilári, Barcelona: Gedisa, 1999b].

Heidegger, M. (GA 53), Hölderlins Hymne “Der Ister” (SS 1942), Walter Biemel (ed.), Frankfurt: Vittorio Klostermann, 1984.

Heidegger, M. (GA 96), Überlegungen XII-XV (Schwarze Hefte 1939-1941), Peter Trawny (ed.), Frankfurt am Main: Vittorio Klostermann, 2014.

Heidegger, M. (GA 97), Anmerkungen I-V (Schwarze Hefte 1942-1948), Peter Trawny (ed.), Frankfurt am Main: Vittorio Klostermann, 2015.

Hülsz Piccone, E. (2009), "Heidegger y Heráclito", en Martín Heidegger: Caminos, Guerra Tejada, R., Yáñez Vilalta, A. (eds.), Cuernavaca: Centro Regional de Investigaciones Multidisciplinarias, Universidad Nacional Autónoma de México.

Hülsz Piccone, E. (2011), Lógos: Heráclito y los orígenes de la filosofía, México D.F.: Universidad Nacional Autónoma de México. 
Lacoue-Labarthe, P. (2002), La ficción de lo político, Miguel Lancho (trad.), Madrid: Arena. Lacoue-Labarthe, P. (2007), Heidegger. La política del poema, José Francisco Megías Flórez (trad.), Madrid: Trotta.

Lacoue-Labarthe, P. (2010), La imitación de los modernos: (Tipografías 2), Cristóbal Durán Rojas (trad.), Buenos Aires: La Cebra.

Lammi, W. (1998), "The Conflict of Paideias in Gadamer's Thought”, en The Paideia Project: Proceedings of the 20th World Congress of Philosophy, https://www.bu.edu/wcp/ Papers/Educ/EducLamm.htm, fecha de consulta: 10/08/2018.

Lotze, H. (1843), Logik, Leipzig: Weidmann.

Nancy, J.-L. (2001), La pensée dérobée, Paris: Galilée.

Nancy, J.-L. (2005), “L' 'etica originaria' di Heidegger”, en íd., Sull'agire. Heidegger e l'etica, trad. it. de A. Moscati, Napoli: Cronopio.

Sullivan, R. (1989), The Early Thinking of Hans-Georg Gadamer, University Park: Pennsylvania State University Press.

Trabattoni, F. (2009), Attualità di Platone. Studi sui rapporti fra Platone e Rorty, Heidegger, Gadamer, Derrida, Cassirer, Strauss, Nussbaum e Paci, Milano: Vita e Pensiero.

Vigo, A. (2008), Arqueología y aleteiología y otros estudios heideggerianos, Buenos Aires: Biblos. 